\title{
Mitochondria, pattern recognition receptors and autophagy under physiological and pathological conditions, including viral infections
}

\author{
Paulina Niedźwiedzka-Rystwej ${ }^{1 \otimes}$, Dominika Bębnowska ${ }^{1}$, Roman Kołacz $^{2}$ and \\ Wiesław Deptuła²
}

IInstitute of Biology, University of Szczecin, Szczecin, Poland; 2Institute of Veterinary Medicine, Faculty of Biological and Veterinary Sciences, Nicolaus Copernicus University in Toruń, Toruń, Poland

\begin{abstract}
Research on the health of mammals invariably shows how dynamic immunology is and how the role of many elements and immune processes of the macroorganism, developed in the process of evolution in protecting against threats, including infections, is changing. Among these elements conditioning the homeostasis of the macroorganism are mitochondria, PRR receptors (pattern recognition receptors) and the phenomenon of autophagy. In the context of physiological and pathological states in the body, mitochondria perform various functions. The primary function of these organelles is to produce energy in the cell, but on the other hand, they are heavily involved in various cellular processes, including ROS production and calcium homeostasis. They are largely involved in the activation of immune mechanisms during infectious and non-infectious conditions through mtDNA and the mitochondrial MAVS protein. Mitochondrial involvement has been also determined in PRR-related mechanisms as mtDNA has the ability to directly stimulate TLRs. On the other hand, mitochondria are also associated with apoptotic cell death and autophagy.
\end{abstract}

Key words: mitochondria, pattern recognition receptors, autophagy

Received: 01 August, 2021; revised: 16 September, 2021; accepted: 26 September, 2021; available on-line: 14 December, 2021

凶e-mail: paulina.niedzwiedzka-rystwej@usz.edu.pl

Abbreviations: APC, antigen presenting cells; ATP, adenosine triphosphate; Bak, BCL2-antagonist/ killer 1; Bax, BCL2 Associated $\mathrm{X}$, Apoptosis Regulator; BCl-2, B-cell CLL/lymphoma 2; CARD, caspase requirement domain; Cardif, CARD-containing adapter protein: DAMP, damage/danger-associated molecular patterns; ER endoplasmic reticulum; FAS, Fas-associated Heath domain; IFN, interferon; IL, interleukin; IPS-I, interferon- $\beta$ promoter stimulator 1; IRF-3, Interferon regulatory factor 3 ; IRF3, interferon regulatory factor 3; LGP-2, Probable ATP-dependent RNA helicase DHX58; LPS, lipopolysaccharide; MAC, mitochondria apoptosis-induced channel; MAPK, mitogen-activated protein kinases; MAVS, mitochondrial antiviral-signaling protein; MDA5, melanoma-differentiation-associated gene 5; mtDNA, mitochondrial DNA; nDNA, nuclear genome; NET, neutrophil extracellular trap; NF-KB, nuclear factor kappalight-chain-enhancer of activated B cells; NLR, Nod-like receptors; NLRP3, NOD-like receptor family pyrin domain containing 3; PAMP, pathogen associated molecular patterns; PINK1, PTEN-induced putative kinase 1 ; PKB, protein kinase $B$; PRR, pattern recognition receptors; PTP, permeability transition pore; RIG-I, retinoic-acidinducible protein 1; RLR, Rig-like receptors; ROS, reactive oxygen species; STING, stimulator of interferon genes; TFAM, mitochondrial transcription factor A; TLR, Toll-like receptors; TRAF3, TNF receptorassociated factor 3; TRIAL, TNF-related apoptosis-inducing ligand; VISA, virus-induced signaling adapter

\section{MITOCHONDRIA AND PHYSIOLOGICAL AND PATHOLOGICAL STATES, INCLUDING VIRAL INFECTIONS}

Mitochondria are cellular structures not only responsible for the production of eneroy necessary for cell metabolism by accumulation of ATP through oxidative phosphorylation, but also the place where genetic material is deposited - methylated $\mathrm{mtDNA}$ and unmethylated DNA called the CpG islands (Choi et al., 2020; Liu et al., 2016; West \& Shadel, 2017). These organelles are also involved in anabolic and catabolic pathways, including regulation of cell signaling, apoptosis, ROS production, and calcium homeostasis (Chelombitko et al., 2020; Choi et al., 2020; Karmakar et al., 2019; Klein et al., 2020). The role of mitochondria is also related to the immune system, including infectious diseases (Choi et al., 2020; Ren et al., 2020). It has been shown that during infection anabolism is changed into catabolism in immune cells, i.e. in T lymphocytes, including Treg, macrophages M1 and M2 (Chelombitko et al., 2020), neutrophils and mast cells (Chelombitko et al., 2020; Klein et al., 2020), thanks to which mitochondria are involved in molecular mechanisms coordinating energy processes (Chelombitko et al., 2020). Mitochondria in the $\mathrm{T}$ effector cells, M1 macrophages and mast cells become fragmented, and in the Treg cells and M2 macrophages they become elongated. This phenomenon determines the regulatory function of mitochondrial morphology, because it is associated with their energy transformation - glycolysis occurs in the $\mathrm{T}$ effector lymphocytes and M1 macrophages, and oxidative phosphorylation and $\beta$-fatty acid oxidation in the Treg lymphocytes and M2 macrophages (Chelombitko et al., 2020).

Through mtDNA and mitochondrial MAVS, mitochondria generate a dynamic "network" capable of expression and signaling leading to activation of immunological factors, including pro-inflammatory cytokines, e.g. type I IFN, which currently includes not only IFN- $\alpha$ and $\beta$, but also $\delta, \varepsilon, x, \theta, \omega, \lambda, \tau, \zeta$ and $\nu$ - important elements of natural immunity, but also in the process of apoptosis and efferocytosis (Bandurska et al., 2014; Chelombitko et al., 2020; Choi et al., 2020; Cloonan and Choi, 2013; Crouse et al., 2015; Pérez-Hernández et al., 2020; Reczek \& Chandel, 2015; Ren et al., 2020). It has also been shown that under physiological and pathological conditions, including viral infections, the constant cleavage and fusion of a number of kinetic proteins in the cell is dependent on the dynamic balance of the mitochondrial network. (Karmakar et al., 2019; Ren et al., 
2020). In the case of infections that interact both, directly and indirectly with the mitochondria via mtDNA and MAVS proteins, they lead to a change in the mitochondrial environment, which may cause disturbances (Chelombitko et al., 2020; Ren et al., 2020). These organelles, by blocking programmed death receptor 1 - PD-1 or cytotoxic $\mathrm{T}$ cell antigen 4 - CTLA- 4 signaling, play a role of immune checkpoint inhibitors which prevents depletion of $T$ lymphocytes (Klein et al., 2020). It has been shown (Kang et al., 2007; West et al., 2015) that mtDNA determines activation of many immune mechanisms that influence health, as the transcription factor TFAM binds to mtDNA, stabilizes its structure and influences the number of its copies. In addition, mtD$\mathrm{NA}$ is responsible for activation of the innate immunity mechanisms related to the signaling pathways of PRR receptors, as mtDNA molecules, due to the presence in the mitochondria of the $\mathrm{CpG}$ islands - elements characteristic for bacterial DNA, are recognized as DAMP (Bandurska et al., 2014; Meyer et al., 2018; Poniewierska-Baran et al., 2018). It has been reported that mtDNA also has the ability to directly stimulate intracellular TLR receptors (Liu et al., 2016; Meyer et al., 2018), which are a marker for cytosolic DNA and endogenous genetic material (Acuña-Castroviejo et al., 2017; Choi et al., 2020). In the absence of direct release of $\mathrm{mtDNA}$ through the mitochondrial pores into the cytoplasm, this process may occur via mitochondrial - derived vesicles MDVs (West \& Shadel, 2017).

The role of mtDNA is also important during inflammatory and infectious processes, as it plays a fundamental role in the formation and activation of a functional receptor, which is the NLRP3 inflammasome (Klein et al., 2020; Liu et al., 2016). It has been shown (RiveraVargas et al., 2017) that the basic form of NLRP3 is located near the ER, but it migrates to the nucleus after stimulation, which puts NLRP3 in contact not only with the mitochondria and ER, but also with the nucleus. Its special features are the ability to recognize a wide spectrum of PAMP and DAMP patterns (Klein et al., 2020; Liu et al., 2016) and the fact that it is an element in the mtDNA migration to the cytosol and is involved in the signaling of IL-1 $\beta$ and IL-18 by macrophages (Karmakar et al., 2019; Rivera Vargas et al., 2017). NLRP3 inflammasome is also involved in the process of $\mathrm{mtDNA}$ release with participation of ATP and the release of mitochondrial reactive oxygen species - mROS. Moreover, oxidized mtDNA shows the ability to directly bind NLRP3 inflammasome, which enhances its activation (Cloonan \& Choi, 2012; Liu et al., 2016). Activation of the NLRP3 inflammasome by mtDNA also occurs due to the presence of bacterial LPS and ATP (Klein et al., 2020; Nakahira et al., 2011).

The role of mitochondria through mtDNA is noticeable in the activation of a pathway associated with the interferon gene stimulating protein STING, which is a key element in the induction of an immune response in viral infections (Ohta \& Nishiyama, 201; Ren et al., 2020; Scott, 2009). STING, belonging to the family of ER-related signaling molecules (Hu et al., 2018; Ohta \& Nishyama, 2011), is necessary for the production of type I IFN in fibroblasts, macrophages and dendritic cells in response to cytoplasmic dsDNA, as well as viral DNA, RNA and DNA of intracellular bacteria (Choi et al., 2020; Hu et al., 2018; Ohta \& Nishyama, 2011; Ren et al., 2020). The incorrect activation of the STING pathway may lead to increased inflammation caused by type I IFN, as well as apoptosis, and even necroptosis and pyroptosis (Luo et al., 2017). The responses of mito- chondrial metabolites also influences the killer functions of macrophages and thus enhances innate immunity (Ren et al., 2020; Sancho et al., 2017). TFAM induced by infection with a herpesvirus causes the loss of stability of the mtDNA molecule, which in turn leads to the release of mtDNA fragments into the cytoplasm (West et al., 2015). These particles trigger a series of messengers in the cytoplasm of the cell, which leads to activation of the STING gene pathway that stimulates kinase 1, which in turn initiates a cascade leading to activation of IRF-3, and which then induces synthesis and activates type I IFN (West et al., 2015) - an element of the innate antiviral immunity (Meyer et al., 2018; Piotrowska et al., 2016; Ren et al., 2020; West et al., 2015).

Antibacterial properties of mtDNA were also recorded (West et al., 2015), resulting from cooperation with eosinophils and Th17 lymphocytes (Acuña-Castroviejo et al., 2017; Chelombitko et al., 2020). In the case of mtDNA of eosinophils, after their stimulation by LPS of Gram-negative bacteria, mechanisms similar to the NET network occur (Acuña-Castroviejo et al., 2017). On the other hand, in the case of mtDNA of Th17 lymphocytes, its effect is manifested by the ability of mtDNA to bind to IL-26 (Acuña-Castroviejo et al., 2017), which leads to stimulation of IFN-secretion by dendritic cells (Acuña-Castroviejo et al., 2017). MtDNA may also bind to natural immune peptides, e.g. cathelicidines - LL37, which leads to stimulation of monocytes and macrophages towards the synthesis of the pro-inflammatory cytokine TNF- $\alpha$ (Acuña-Castroviejo et al., 2017). Summary of the role of $\mathrm{mtDNA}$ in a macroorganism is presented in Fig. 1.

The stimulation with PAMP molecules of the MAVS protein (also referred to as VISA, Cardif or IPS-I) (Popkov et al., 2016), which is located on the outer surface of the mitochondrial membrane (Meyer et al., 2018; West and Shadel, 2011, similarly to mtDNA, leads to the activation of many elements of immunity (Huang et al., 2015; Poyton et al., 2009; Ren et al., 2020), especially components of the innate antiviral response (Meyer et al., 2018; Ren et al., 2020; West and Shadel, 2011). It has been reported that the abnormally functioning MAVS protein is associated not only with the occurrence of hepatitis $\mathrm{A}, \mathrm{B}$ and $\mathrm{C}$ virus infections, cytomegalovirus, reproductive and respiratory syndrome virus and vaccinia virus, but also with increasing inflammation in the course of non-infectious diseases in the fatty liver dis-

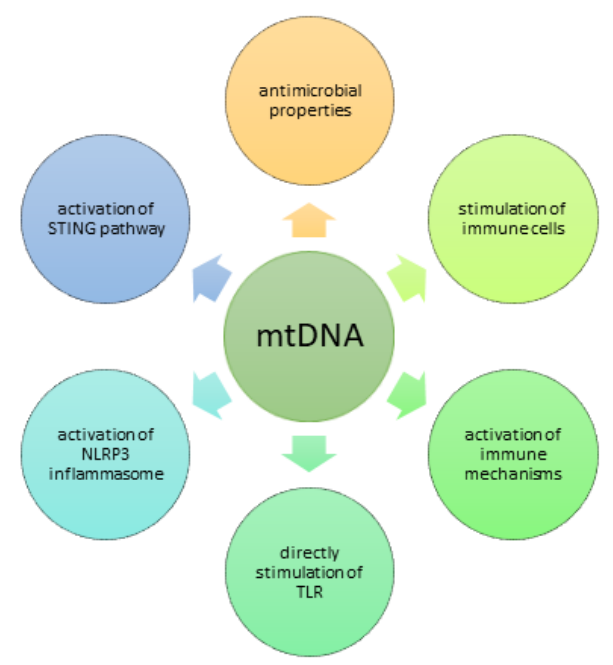

Figure 1. The role of mtDNA under physiological and pathological conditions. 
ease and systemic lupus erythematosus (Cloonan \& Choi, 2012; Ren et al., 2020). It has been shown that the Cardif protein, also present in the cytosolic receptors RIG-I and MDA5, is involved in detection of genetic material of viruses not only at the stage of their infection, but also at the stage of their replication (Monlun et al., 2016; Scott, 2009). This applies in particular to the RNA viruses characterized by high variability (Millis et al., 2017). It should be added that RIG-I receptors recognize not only the 5 'phosphorylated ssRNA viruses with positive and negative polarity (Liu et al., 2016), but also dsDNA viruses (Monlun et al., 2016), including paramyxoviruses, the influenza virus and Japanese encephalitis virus, where such an infection induces the synthesis of INFs ( $\mathrm{Hu}$ et al., 2018). On the other hand, MDA5 receptors and the mitochondrial MAVS proteins interacting with them are key receptors in immunity against picornaviruses ( $\mathrm{Hu}$ et al., 2018), although they also bind the viral genetic material of dsRNA (Liu et al., 2016). It was recorded that the length of the viral genetic material chain determines participation of an appropriate receptor. RIG-1 tags bind relatively short fragments of dsRNA (21-27 nucleotides in length), and the MDA5 tag inclines towards the recognition of fragments longer than $2 \mathrm{kbp}$ (Monlun et al., 2016). Binding of RIG-I and MDA5 receptors with the mitochondrial protein MAVS also triggers a reaction cascade that activates the transcription factors IRF3 and $\mathrm{NF}-x \mathrm{~B}$, which leads to the synthesis of IFN- $\beta$ (Khan et al., 2016; Vazquez \& Horner, 2015). Activity of the MAVS protein is regulated by various mechanisms arising during the antiviral response, in which the mRNA level of this protein is maintained at an appropriate level due to the negative ROS feedback (Ren et al., 2020; $\mathrm{Xu}$ et al., 2012). It has been reported that during viral infections, formation of large MAVS aggregates occurs through the produced "prion-like" fibrils, which have a strong stimulating effect on the cytosolic IRF3, showing the ability to transform endogenous MAVS into functional aggregates (Hou et al., 2011). Studies have shown (Hu et al., 2018) that the DNA of adenoviruses and herpesviruses, i.e. the Epstein-Barr virus and herpes simplex virus 1 , induce INF- $\beta$ expression through RIG-1 stimulation (Hu et al., 2018). It was reported (Hu et al., 2018) that the DNA-dependent RNA polymerase III (Pol-III) of adenoviruses and HSV-1, responsible for the synthesis of 5'-triphosphate RNA from cytoplasmic poly (dA-dT) DNA, is an intense mediator in the signaling reaction associated with the RIG-1 receptor which is in part the role of these receptors in detecting and neutralizing RNA and DNA viruses (Hu et al., 2018). It was also reported that activation of RIG-1 and MDA5 leads to initiation of reactions leading to activation of $\mathrm{NF}-x \mathrm{~B}$ transcription factors and production of pro-inflammatory cytokines, as well as activation of IRF and induction of type I IFN synthesis (Monlun et al., 2016). Moreover, the process of oligomerization of the CARD domain of the RIG-1 receptor enables CARD to bind to the mitochondrial MAVS protein, which activates the tumor necrosis factor receptor type 1-associated death domain - TRADD protein (Monlun et al., 2016). This condition results inactivation of two alternative signaling pathways, i.e. the TRAF3 protein-dependent pathway, which ends with the synthesis of type I IFN, and the other FAS protein-dependent pathway, leading to activation of inhibitor of $x \mathrm{~B}$ which undergoes phosphorylation and destruction in the proteasome, and leads to the release of $\mathrm{NF}-x \mathrm{~B}$, which strongly activates the synthesis of proinflammatory cytokines after translocation to the nucleus
(Monlun et al., 2016). Summary of the role of the MAVS protein in a macroorganism is presented in Fig. 2.

Involvement of mitochondria is important in the early phase of viral infection due to interactions of inflammatory mediators reacting with receptors that recognize the PRR patterns, which leads to activation of signaling pathways, e.g. transcription factor NF- $x \mathrm{~B}, \mathrm{MAPK}$ and $\mathrm{PKB}$ (Ren et al., 2020). Under these conditions expression and activity of coactivators and transcription factors, such as Peroxisome proliferator-activated receptor gamma coactivator1- $\alpha$ ), Nuclear respiratory factor 1 and Nuclear factor (erythroid-derived2-like 2) (Cherry \& Piantadosi, 2015; Ren et al., 2020), are increased which results in activation of the defense process of apoptosis (Ren et al., 2020). During a viral infection, if the signal comes from outside the cell, the ligand binds to the membrane receptor and, as a result, activates caspases in the external and internal apoptotic pathway and cell death (Deptuła et al., 2006; Niedźwiedzka-Rystwej \& Deptuła, 2009; Ren et al., 2020). Moreover, in the case of the intrinsic apoptotic pathway, mitochondria are direct receivers of the pro-apoptotic signals from inside the cell (Ren et al., 2020). In the case of the extrinsic apoptotic pathway, it is triggered by ligand binding to death receptors, which include CD95/FasL, the tumor necrosis factor receptor TNF- $\alpha$, and receptor 1 and 2 related to TNF-dependent receptor from apoptosis - TRIAL (Hu et al., 2018), while in the internal apoptotic pathway these reactions occur through mitochondrial PTP mega canals, located in the area where both mitochondrial membranes meet, and therefore mitochondria are key elements in these responses (Jóźwiak \& Marczak, 2006; Ren et al., 2020).

The defensive role of mitochondria in the macroorganism is also realized through the process of apoptosis, which occurs as a result of various types of stimuli, including oxidative stress, DNA damage, electrolyte transport disturbances, increase in calcium ion concentration and increase in ROS concentration in the cytoplasm of the cell (Chelombitko et al., 2020; Cloonan \& Choi, 2013; Jóźwiak \& Marczak, 2006). Activation of apoptosis also occurs because of a change in the membrane potential and disruption of the continuity of the mitochondrial membrane which is observed during viral infections (Chelombitko et al., 2020; Cloonan \& Choi, 2013; Ren et al., 2020). It has been shown that after opening the PTP mitochondrial mega canals, one of the elements permitted through the membrane is cytochrome $c$, which after getting into the cytosol is combined with apoptotic

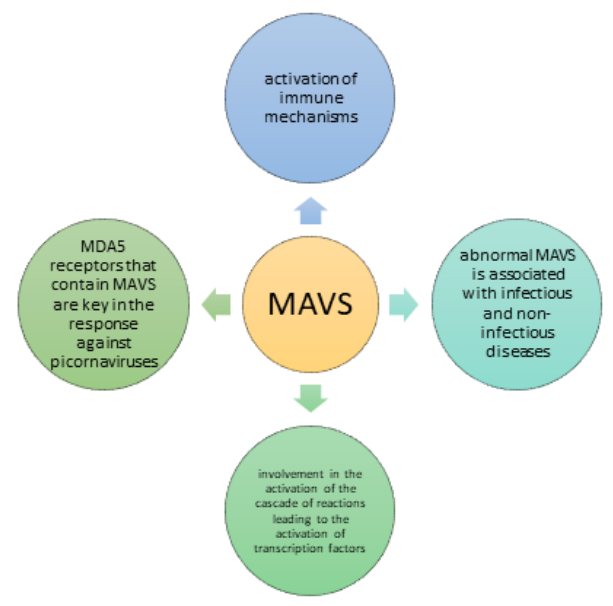

Figure 2. The role of the MAVS protein under physiological and pathological conditions. 
protease activating factor 2 and procaspase 9, the effect of which is the so-called apoptosome whose role is to mobilize caspase 9, initiating the cascade of changes leading to cell death (Jóźwiak \& Marczak, 2006). Moreover, when caspase 8 is activated in both, the internal and external apoptotic pathways, the permeability of the mitochondrial membrane and the release of cytochrome $c$ is increased, which occurs by opening not only PTP but also MAC channels that arise at early stages of programmed cell death (Cloonan \& Choi, 2013; Liu et al., 2014; Peixoto et al., 2011). It has been proven (Labędzka et al., 2006) that MAC channels are regulated by proteins of the Bcl-2 family which are the group of the most known proteins regulating the apoptotic pathway, among which there are both, the proteins that inhibit this process and pro-apoptotic ones, i.e. the Bax and Bak proteins. Activation of these proteins leads to the release of cytochrome $\mathrm{c}$ and the apoptosis inducing factor (Scott, 2009).

It has been shown that during a viral infection, synthesis of factors affecting apoptosis occurs due to "unfolding" of specific strategic mechanisms by viruses aimed at avoiding the immune response and releasing progeny particles during infection (Chmielewska et al., 2017; Cloonan \& Choi, 2013; Labędzka et al., 2006; Ren et al., 2020). This is the case for the Epstein-Barr virus, African swine fever, cytomegalovirus, hepatitis B and C virus, as well as PRRSV and rotavirus, as they have, inter alia, the ability to synthesize caspase inhibitors that inhibit apoptosis, including ability to recruit Bax proteins to mitochondria (Galluzil et al., 2008; Ren et al., 2020). However, in the case of the herpes simplex virus and the human papillomavirus, both inhibitory and stimulating effects on apoptosis occur (Halford et al., 2001; Miszczak, 2013). In the case of a rabies virus infection, it was shown that the $\mathrm{M}$ protein of this virus, acting on mitochondria, induces mitochondrial programmed cell death at the late stages of infection through caspasedependent and independent pathways (Xu et al., 2012), which was also observed for rotavirus infections (Ren et al., 2020). Hence, it can be concluded that the role of mitochondria in the process of apoptosis in viral infections, through mitochondrial cleavage and then their fusion, leads to enhancement of the immune status of the macroorganism and the virus removal, although this process may also affect the replication of viruses (Cloonan \& Choi, 2013; Ren et al., 2020). It has been reported that if apoptosis occurs at the viral replication stage, the process is fruitless, and if it is related to the virus entry into the cell, it is effective (Ren et al., 2020). It has been also described that syncytial viruses, including the Newcastle disease virus, cause cell death by formation of syncytium - multinucleated cells, and in the case of the Coxsackie $B$ virus infection, extracellular microbubbles are released (Ren et al., 2020), and the Epstein-Barr virus causes migration of cells leading to tumor formation as a result of disturbances in the dynamics of mitochondria (Ren et al., 2020).

The role of mitochondria is also related to the expression of nuclear genes, and then differentiation of stem cells, and thus by affecting the immune system mitochondria participate in the inflammatory response and diseases of the infectious and non-infectious background (Chelombitko et al., 2020; Poyton et al., 2009; Ren et al., 2020; Tokarz and Blasiak, 2014). Their role was recorded, inter alia, in non-infectious diseases, e.g. non-alcoholic fatty liver, as a result of increased mitochondrial fatty acid oxidation (Murphy \& Hartley, 2018). Moreover, it is possible to use mitochondrial therapies in the treat- ment of viral (Choi et al., 2020) and parasitic infections caused by Trypanosoma (T.) cruqi, T. brucei and Plasmodium falciparum protozoa, as well as in non-infectious diseases, such as retinal dysfunction and heart failure (Murphy \& Hartley, 2018).

Mitochondria are associated with such processes as aging, as described, among others, in the Mitochondrial Free Radical Theory of Aging (Reczek \& Chandel, 2015; Sanz \& Stefanatos, 2008; Tokarz \& Blasiak, 2014), which assumes that the accumulation of ROS produced by these organelles causes damage to nucleic acids and proteins (Bernhardt et al., 2014; Chang et al., 2015; Chelombitko et al., 2020) and leads to mutational changes in mtDNA (Chelombitko et al., 2020; Ren et al., 2020). It is assumed that mutations in the mitochondrial genome and oxidative damage in cellular components significantly affect the impairment of a macroorganism's functions, including defense, and this also initiates the aging process (Molnar \& Covacs, 2018). It has been shown that enzymatic proteins play an important role in regulation of the antioxidant system of the macroorganism, including mitochondria which catalyze transformation of ROS into less toxic compounds (Choi et al., 2020; Karmakar et al., 2019; Klein et al., 2020; Ren et al., 2020). These substances (Choi et al., 2020) also determine the viability of the macroorganism, because it has been shown that inactivation of one of the five mitochondrial superoxide dismutase in Caenorbabditis elegans results in prolonged viability of this nematode (Chang et al., 2015). In these studies (Chang et al., 2015), it was also observed that only certain mutations within the enzyme-forming subunits in the mitochondrial electron transport pathway reduced the viability of Caenorhabditis elegans (Chang et al., 2015). Also, mutants of this animal with various levels of viability are silenced for relevant genes in the mitochondrial pathway, which causes disturbances in nutrition and defecation, as well as slower growth and reduced mass of this nematode (Chang et al., 2015). Summing up, the role of mitochondria in this matter is not obvious, being a kind of a double-edge sword. Research conducted on Drosophilia melanogaster and rodents from the Muridae family also confirm impact of disturbances in the mitochondrial electron transport pathway on the lifespan of these animals (Tokarz \& Blasiak, 2014). In the case of mice with a mutation in the mitochondrial gamma polymerase gene, a decrease in their viability was recorded (Tokarz \& Blasiak, 2014). Moreover, studies conducted (Pérez-Hernández et al., 2020) on mitochondria during initial stage of innate immunity with participation of fumarate, a mitochondrial metabolite, had shown that its use caused an immediate effect of mitochondrial activation both in the human monocytes and in the organism of C. elegans, which was accompanied by their fusion, polarization and the approach of intra-mitochondrial folds, as well as the influx of calcium into the cytoplasm. Moreover, in the case of $C$. elegans, mitochondrial fusion in these animals was accompanied by an increase in resistance to an Escherichia coli infection (Pérez-Hernández et al., 2020).

The accumulation of mutations within mtDNA, disrupts the functioning of the mitochondria, which may contribute to the initiation of processes resulting from their cleavage and fusion, which results in inflammation, metabolic syndromes and heart diseases, neurodegenerative diseases and neoplasms (Gregorczyk, 2017; Klein et al., 2020; Ren et al., 2020; Shefa et al., 2019). It has been shown that insufficient intensification of the process of removing damaged mitochondria in the mitophagy process (Meyer et al., 2018) results in accumulation of ROS 
in the cell, which leads to formation of defects in the mitochondrial and nuclear genetic material, which then leads to formation of neoplastic changes (Meyer et al., 2018; Ren et al., 2020; Shefa et al., 2019). In the case of insufficient intensification of mitochondrial "utilization", which is necessary at the initial stages of carcinogenesis, this process remains also an indispensable element in the further stages of oncogenesis (Shefa et al., 2019). It has been described that the process of carcinogenesis may be supported by ROS as these compounds affect the mitochondria and the cell nucleus, and thus affect various processes in the cell, including DNA damage, inactivation of suppressive proteins, or even activation of proto-oncogenes and cell proliferation (Tokarz \& Blasiak, 2014; Czarnecka et al., 2011; Klein et al., 2020).

It has been observed that the resulting mtDNA damage has a significant impact on the events leading to an increase in ROS production, which in turn increases the oxidative stress and leads to the activation of signaling pathways towards increased proliferation and formation of the neoplastic process (Craven et al., 2017). These mtDNA changes can occur as a result of various events, including mutations in mtDNA coding sequences, or changes in the number of mtDNA copies (Craven et al., 2017). These predilection mutational changes in mtDNA are observed within the D-loop (D-loop or Displacement loop), which is conditioned by the presence of a triple-stranded structure (Craven et al., 2017). It should be emphasized that the loop-D sequences play an essential role in the process of $\mathrm{mtDNA}$ replication and transcription, and also play a role in its stabilization (Tokarz \& Blasiak, 2014). "Errors" in the mtDNA structure may also arise as a result of instability of mtDNA microsatellite sequences and as polymorphic changes in the $\mathrm{D}$ loop, mainly in the poly-C sequence at positions 303-309 (Tokarz \& Blasiak, 2014), while changes in microsatellite sequences are found primarily in the form of insertions and deletions (Craven et al., 2017), which were recorded in cancer of the stomach, breast, esophagus, glioblastoma multiforme, ovarian cancer, prostate cancer - Prostate Intraepithelial Neoplasia, lung and head and neck cancers (Craven et al., 2017). The Leber's hereditary optic neuropathy is also one of the diseases associated with point mutations in mtDNA (Tońska et al., 2018).

It has been reported that changes damaging mtDNA in the mitochondrial apoptosis pathway lead to increased survival of cells entering the carcinogenic pathway, as well as increased resistance to anticancer drugs (Tokarz \& Blasiak, 2014). Studies by Huang and others (Huang et al., 2015) indicate that by reducing expression and oligomerization of pro-apoptotic $\mathrm{Bak}$ proteins located in the mitochondria, it is possible to induce apoptosis in neoplastic cells by treating them with NPM - N-(1pyrenyl) maleimide, which shows a cytotoxic effect on neoplastic cells (Huang et al., 2015). It should be added that many oncogenic viruses encode homologues of antiapoptotic $\mathrm{Bcl}-2$ proteins, which disrupt the functioning of the mitochondria. As a result, neoplastic processes induced by oncogenic viruses are initiated (Cavallari et al., 2018). It has been proven that the $\mathrm{Bcl}-2$ protein regulates not only the energy balance of the cell by influencing the electron transport chain and mitochondrial inner membrane complexes, but also the mitochondrial $\mathrm{Ca}^{2+}$ ion economy and ROS production (Cavallari et al., 2018). It is assumed that the discovery of the possibility of artificial induction of the apoptotic pathway, e.g. via mitochondria, including their oxidative phosphorylation which is an important component for cancer cell survival or ROS production, is a promising target for the de- velopment of new, effective and non-invasive anti-cancer therapies (Murphy \& Hartley, 2018). Disturbances in the mitochondria can also cause neurodegenerative diseases, such as Alzheimer's, Parkinson's, Huntington's, and Amyotrophic lateral sclerosis (ALS) (Bernardini et al., 2016; Murphy \& Hartley, 2018; Ren et al., 2020). It has been shown that changes in mtDNA registered in the cells of the brain, heart and skeletal muscles in humans (Tokarz \& Blasiak, 2014) may be the cause of muscle weakness, neurological diseases or lactic acidosis (Chang et al., 2015; Durhuus et al., 2014). It has been reported that as many as $72-85 \%$ of various pathological conditions may be the cause of mitochondrial abnormalities, including mutations in the nDNA, as most mitochondrial proteins are encoded by nDNA (Pronicka et al., 2008; Tońska et al., 2018).

It is worth adding that the phenomenon of heteroplasmy - the presence of more than one type of mtDNA, is characterized by the presence of genetic material with the correct sequence and that with defective, burdened with mutational changes (Tońska et al., 2018), which usually cause disease symptoms with $60-80 \%$ of defective mtDNA molecules. These genetic conditions negatively affect the energy processes taking place in the cell in the mitochondria, which have been identified in relation to diseases resulting from deficits in the respiratory chain (Piętka et al., 2008). It has been reported that the underlying cause of disease in children with the Leigh's syndrome is deficiency of the surfeit locus protein 1 which participates in the assembly of complex IV of the respiratory chain running in the mitochondria (Piętka et al., 2008). In the course of this disease, apparently healthy children begin to experience many disease symptoms less than a year after birth due to progressive encephalopathy, which leads to death before reaching 4 years of age (Piętka et al., 2008). Moreover, there are assumptions that disturbances in the delivery of ATP which is produced in the mitochondria to the brain cells may contribute to an increased susceptibility to migraine attacks (Fila et al., 2018). One of the common pathologies closely related to mitochondrial dysfunction in humans is the Lefora's disease which manifests itself in progressive myoclinic epilepsy, ataxia, psychosis and dementia, which may also occur as a result of pathological activation of the p53 protein (Durhuus et al., 2014). Impairment of mitochondrial function in humans is also associated with formation of insulin resistance, as reduced biogenesis of mitochondrial proteins and inhibition of oxidative protein activity leads to accumulation of fatty acids, including diacylglycerols and ceramides that can inhibit insulin signaling (Montgomery \& Turner, 2015; Murphy \& Hartley, 2018).

Also, inhibition of certain processes in the electron transport pathway was found in a study of mutations within individual subunits involved in cellular respiration (Chang et al., 2015). This process occurs as a result of mitophagy, which is the process by which mitochondria are degraded in the autophagolysosomes. This process is initially characterized by the fact that mitochondria are fragmented by the dynamin related protein 1 (Hamacher-Brady \& Brady, 2016). The resulting new "organelles" are divided into polarized "structures" that can undergo fusion and those whose membranes are depolarized and eventually degraded during mitophagy (Bednarczyk et al., 2016). This process is regulated by the PINK1 kinase and ubiquitin ligase paracetase, hence in the "healthy" mitochondria the level of PINK1 is kept low, which prevents organelles from entering the path of mitophagy. It should be added that at the initial stage of 
mitophagy, PINK1 recruits on the surface of mitochondria the Parkin protein found in the cytosol, which leads to activation of the E3 Parkin ligase and involvement of a number of additional proteins in the mitophagy process which play an important role in the initiation of this phenomenon (Lenart, 2017). It is worth noting that mitophagy is a process that affects cells in the period of adaptation to their functions, e.g. it concerns the removal of mitochondria in mature erythrocytes, which is an element necessary for the transport of hemoglobin by these cells (Piotrowska \& Bartnik, 2014). An example of mitophagy is also the process of removing paternal mitochondria from a fertilized egg, which further explains the inheritance of mtDNA in the maternal line (Piotrowska \& Bartnik, 2014). Disturbances in mitochondrial dynamics in the field of electron transport result, among others, in fission of mitochondria, mitophagy and apoptosis of cells, including the nerve cells, that are recorded in viral infections (Ren et al., 2020). These processes suppresses the immune response and weakens the immune status of the organism (Ren et al., 2020).

\section{PRR RECEPTORS AND AUTOPHAGY VERSUS PHYSIOLOGICAL AND PATHOLOGICAL STATES, INCLUDING VIRAL INFECTIONS}

Among elements that affect macroorganism's hoomeostasis, including the immune system, and thus are important under physiological and pathological states, are pattern recognition receptors (PRR), whose task is to recognize molecular patterns of pathogens - PAMP, but also patterns associated with the danger - DAMP (Deptuła et al., 2006). PRR markers are divided into: secreted receptors (opsonins, collectins, phicolins and pentaxins), - receptors initiating phagocytosis - the socalled endocytic (transmembrane proteins mediating the internalization of pathogens, mannose receptor and scavenger receptors) - and signaling receptors (Deptuła et al., 2006). The latter markers include transmembrane TLR receptors and typical cytosolic receptors, which include RLR, NLR, and functional receptors - inflammasomes (Niedźwiedzka-Rystwej et al., 2016).

TLR receptors are present on the cell membrane, but also inside the cell, where they are responsible, among others, for the detection of components of microorganisms, including viruses (Thompson \& Locarnini, 2007). In the case of infectious agents, including viruses that "penetrated" the immune barrier created on the cell membrane, conditioned by TLR, at a later stage intracellular RLR receptors are mainly involved in antiviral defense, including RIG-I, MDA5 and LGP2 (Cloonan \& Choi, 2013), NLR e.g. NOD2 and the NLRP3 inflammasome (Chen \& Ichinohe, 2015; Jacobs \& Domania, 2012; Śliwa-Dominiak \& Deptuła, 2011; Śliwa-Dominiak et al., 2014). Among intracellular TLRs that detect viral PRR patterns, including patterns in the form of unmethylated DNA, the TLR3, TLR7, TLR8 and TLR9 receptors should be mentioned (Thompson \& Locarnini, 2007), as well as RLR tags (RIG-1, MDA5, LGP2) that recognize viral ssRNA, dsRNA and its synthetic analog - poly (I: C) (polyriboinosyl: polyribocytidyl acid) and NLR tags, including NOD and NLRP3, that recognize mainly viral dsRNA (Ren et al., 2020; Śliwa-Dominiak \& Deptuła, 2011). Intracellular TLR3 receptors have been shown to recognize dsRNA viruses, and TLR 7 and 8 recognize ssRNA viruses, while TLR9 recognize viral dsDNA, which contains unmethylated DNA together with CpG islands (Xagorari \& Chlichlia, 2008).
Intracellular TLRs 3, 7, 8 and 9, after recognizing viral genetic material, trigger the synthesis of type I IFN which is immunostimulatory and in particular induces antiviral immunity (Xagorari \& Chlichlia, 2008). It has been also reported that TLR3, recognizing purified dsRNA from reovirus-1 and poly (I: C), causes the synthesis of IFN- $\beta$, IL-12, IL- 6 and TNF- $\alpha$ (Hewson et al., 2005). In turn, by detecting viral ssRNA, TLR7 and TLR8 activate separate signaling pathways that contribute to formation of various phenotypes of immune system cells (de Marken et al., 2019). Studies have shown (de Marken et al., 2019) that signaling through TLR7 increases expression of the transcription factor fos-1 (FOS1), which decreses production of IL-27 and TNFalpha, and inhibits the type I IFN response (de Marken et al., 2019). In addition, in the case of TLR9, these markers recognize unmethylated $\mathrm{CpG}$ islands commonly found in viral and bacterial DNA and activate plasmacytoid dendritic cells (pDCs) and other DC types, as found for infections with Murine cytomegalovirus, Herpes simplex virus 1, Herpes simplex virus 2 and poxviruses. It was also reported that the varicella zoster virus and cytomegalovirus, via the TLR9, trigger production of IFN- $\alpha$ (Lester and Li, 2014). On the other hand, cytosolic RLR receptors, after recognizing viruses, activate $\mathrm{NF}-x \mathrm{~B}$ and IRF-3, which leads to production of IFN type I and proinflammatory cytokines, such as: IL- 1 and TNF- $\alpha$ (Cloonan \& Choi, 2013; Śliwa-Dominiak et al., 2014). It has been shown that production of type I IFN induced by these receptors stimulates differentiation, maturation and migration of APC, proliferation of natural killer cells, as well as increased expression of MHC class I receptors on immune cells, resulting in activation of the immune response and increase in immunity (Cloonan \& Choi, 2013; Śliwa-Dominiak \& Deptuła, 2011; Śliwa-Dominiak \& Deptuła, 2011a).

It has been shown that during viral infections, RLR receptors can be blocked by viruses which reduces expression of the type I IFN genes and lowers immunity, and thus weakens the immune response (Cloonan \& Choi, 2013; Śliwa-Dominiak \& Deptuła, 2011; ŚliwaDominiak \& Deptuła, 2011a). Such a state may arise during the initial phase of viral infection, during transmission of signals activating expression of mainly type I IFN, that involves many viral proteins, which has been observed, among others, in the case of hepatitis A, B and $C$ viruses, influenza $A$, vaccinia, Ebola and rabies (Ramos \& Gale, 2011).

It has been also reported that other intracellular markers - NLR, affect the immune status by reacting with PAMP and DAMP markers (Chen \& Ichinohe, 2015; Poniewierska-Baran et al., 2018; Śliwa-Dominiak \& Deptuła, 2011; Śliwa-Dominiak \& Deptuła, 2011a). It has been reported that stimulation of NLR receptors by viral PAMP markers leads to activation of caspase-1 and synthesis of mature forms of IL-1, which induces inflammatory responses, including activation of anti-apoptotic signaling mediated by IL-2R, and stimulates effector lymphocytes and regulatory, as well as B lymphocytes (Tokarz-Deptuła et al., 2011). Moreover, stimulation of viral NLR receptors also leads to the release of IL-18 which promotes activity of the Th2 lymphocytes and enhances synthesis of INF- $\gamma$ and cytotoxicity of natural killer cells (Tokarz-Deptuła et al., 2011). It has been shown that under the influence of viral ssRNA, NLR markers bind to IPS-1 which also strongly activates synthesis of type I IFN (Crouse et al., 2015). During a viral infection, NLRs also affect the immune system of the macroorganism by activating the mitochondrial MAVS protein 
Table 1. Signal receptors activated in infectious states and their function.

\begin{tabular}{|c|c|c|c|}
\hline $\begin{array}{l}\text { Receptor } \\
\text { group }\end{array}$ & Receptor type & $\begin{array}{l}\text { Recognized genetic } \\
\text { material }\end{array}$ & Consequence of stimulation \\
\hline \multirow{3}{*}{ TLR } & TLR3 & dsRNA & $\begin{array}{l}\text { activation of IFN type l; } \\
\text { after recognition of the reovirus dsRNA and poly (I: C), TLR } 3 \text { causes the synthesis } \\
\text { of IFN- } \beta \text {, IL-12, IL-6, TNF-a }\end{array}$ \\
\hline & $\begin{array}{l}\text { TLR7 } \\
\text { TLR8 }\end{array}$ & ssRNA & $\begin{array}{l}\text { activation of IFN type I; } \\
\text { TLR } 7 \text { and TLR8 activate signaling pathways that lead to different phenotypes of } \\
\text { immune cells; } \\
\text { TLR7 increases expression of FOS1 which causes a decrease in the production of } \\
\text { IL-27, TNF- } a \text { and inhibition of the response with IFN type l; }\end{array}$ \\
\hline & TLR9 & $\begin{array}{l}\text { dsDNA } \\
\text { CpG islands }\end{array}$ & $\begin{array}{l}\text { activation of IFN type I; } \\
\text { activation of pDC and other types of DCs; } \\
\text { affects the production of IFN- } a \text {; }\end{array}$ \\
\hline RLR & $\begin{array}{l}\text { RIG-I } \\
\text { MDA5 } \\
\text { LGP2 }\end{array}$ & $\begin{array}{l}\text { ssRNA } \\
\text { dsRNA } \\
\text { poli }(l: C)\end{array}$ & activation of NF-KB and IRF-3, leading to the synthesis of type I IFN, IL-1, TNF-a; \\
\hline NLR & $\begin{array}{l}\text { NOD2 } \\
\text { NLRP3 }\end{array}$ & dsRNA & $\begin{array}{l}\text { PAMP stimulation leads to caspase- } 1 \text { activation and IL-1 synthesis; } \\
\text { NLR stimulates the secretion of IL-18; } \\
\text { MAVS and mitophagy activation; } \\
\text { NLRP3 converts procaspases into caspases and, through IL-1 } \beta \text { and IL-18, initiates } \\
\text { inflammation and pyroptosis in infected cells }\end{array}$ \\
\hline
\end{tabular}

and activating mitophagy (Chen \& Ichinohe, 2015; Mills et al., 2017; Ren et al., 2020). It has been also described that the activated intracellular marker - the NLRP3 inflammasome, converts procaspases into active caspases through its CARD domain, and through caspase-1 initiates a pro-inflammatory response through IL-1 $\beta$ and IL-18 and death of infected cells by pyroptosis, taking part in health and disease (Niedźwiedzka-Rystwej et al., 2016).

The signal receptors involved in infectious states in the macroorganism and the consequences of their activation are summarized in Table 1.

An important process conditioning proper homeostasis and immune status of the organism is the phenomenon of autophagy which is important for the macroorganism especially in the case of nutrient deficiency during infection (Dinkins et al., 2015; Tal and Iwasaki, 2011; Tokarz-Deptuła et al., 2011), as well as the neoplastic process (Dinkins et al., 2015; Niedźwiedzka-Rystwej \& Deptuła, 2009, Świderek \& Strządała, 2013). This process is indispensable when it is necessary to degrade one's own cellular components, which is recorded under physiological states in the mammary gland of mammals during the "dry" period (Lee et al., 2007; NiedźwiedzkaRystwej \& Deptuła, 2009; Tal \& Iwasaki, 2011). During infection, this occurs as a result of inhibiting of the secretion of pro-inflammatory IL-1 $\beta$ and limiting the effects of inflammatory reactions, that inhibits the formation of tissue damage, which is part of the maintenance of proper homeostasis of the organism, and thus good immune status (Dinkins et al., 2015; Tokarz-Deptuła et al., 2011).

The autophagy process is carried out by monocytes, B lymphocytes, dendritic cells and epithelial cells (Niedźwiedzka-Rystwej \& Deptuła, 2009). It is associated with TLR receptors (Cadwell et al., 2008; Lee et al., 2007; Niedźwiedzka-Rystwej \& Deptuła, 2009), as they play a key role in antigen presentation and pathogen degradation by presenting internalized viral ligands to pDC cells (Śliwa-Dominiak \& Deptuła, 2011; Tal \& Iwasaki, 2011). This condition leads to the synthesis of pro-inflammatory cytokines, including type I IFN and chemokines (Tal \& Iwasaki, 2011). It has been proven that the ssRNA viruses, e.g. the Sendai virus or vesicular stomatitis, are recognized through intracellular TLR7 during autophagy, thanks to which the viral RNA is enclosed inside the lysosomal vesicle (Tal \& Iwasaki, 2011). It has been observed that during autophagy of single- and doublestranded RNA viruses in the lysosomal vesicle, secretion of IFN- $\alpha$ is stimulated (Cadwell et al., 2008; Tal \& Iwasaki, 2011; Nakai et al., 2007). NLRs are also involved in the process of autophagy during viral infections (Jacobs \& Domania, 2012).

During mitochondrial autophagy - mitophagy, accumulation of reactive oxygen species - ROS in the cell is an important indicator assessing the state of homeostasis and antiviral immunity (Tal \& Iwasaki, 2011). It has been shown that ROS accumulation influences carcinogenesis because these compounds not only initiate mutations within the host cell DNA, but also inactivate mitochondrial functions and inhibit pro-apoptotic processes, leading to the development of neoplastic diseases (Dinkins et al., 2015; Niedźwiedzka-Rystwej \& Deptuła, 2009; Reczek \& Chandel, 2015). Mitochondrial autophagy - mitophagy is also associated with hypoxia resulting from ATP deficiency and pathological activation of the mitochondrial protein BCL2/adenovirus E1B $19 \mathrm{kDa}$ protein-interacting protein 3 (Świderek \& Strządała, 2013).

The process of autophagy, enabling access to nutrients stored in the tumor cell structures, causes the development of tumor resistance to anti-angiogenic therapy (Świderek \& Strządała, 2013) and, depending on the type and genetic conditions, may protect the macroorganism against neoplasms (Choi, 2012; Kimura et al., 2013). This is due to the fact that if the elements of oxidative stress - ROS are removed, autophagy contributes to tumor elimination, while when this stress is prevented, it causes an increase in the activity of oncogenes and tumor growth. The involvement of autophagy has been also recorded in the Parkinson's and Alzheimer's disease, as in these diseases, e.g. due to damage to the mitochondria, autophagy is impaired (Pickerell et al., 2015). It has been also described that under conditions of weakened autophagy, the cells become "cluttered" which may lead to such diseases as heart failure (Hidvegi et al., 2010), cardiomyopathy (Nakai et al., 2007), Leśniewski-Crohn's 
Table 2. Summary of the role of mitochondria under physiological and pathological conditions.

\begin{tabular}{|c|c|}
\hline Physiological condition & Pathological condition \\
\hline oxidative phosphorylation (ATP) & $\begin{array}{l}\text { mitochondria are involved in apoptosis during infection, and this } \\
\text { can affect viral replication/virus removal }\end{array}$ \\
\hline location of deposit of mtDNA and CpG islands & $\begin{array}{l}\text { increasing mitochondrial fatty acid oxidation can cause the fatty } \\
\text { liver disease }\end{array}$ \\
\hline Regulation of cell signaling & $\begin{array}{l}\text { accumulation of mtDNA mutations may affect metabolic syndromes } \\
\text { and carcinogenesis }\end{array}$ \\
\hline ROS production & diseases caused by mtDNA heteroplasmy \\
\hline Calcium homeostasis & $\begin{array}{l}\text { diseases caused by mitochondrial dysfunction: Leigh's syndrome, } \\
\text { Leber's disease, insulin resistance }\end{array}$ \\
\hline participation in the apoptotic pathway & related to the aging process of the organism \\
\hline activation of type I IFN & $\begin{array}{l}\text { abnormally functioning MAVS protein is associated with the occur- } \\
\text { rence of hepatitis A, B, C, cytomegalovirus infections, Reproductive } \\
\text { and Respiratory Syndrome Virus (PRRSV) and Vaccinia virus }\end{array}$ \\
\hline activation of NLRP3 inflammasome & $\begin{array}{l}\text { abnormal MAVS protein is associated with increased inflammation } \\
\text { in the course of non-infectious diseases, including systemic lupus } \\
\text { erythematosus }\end{array}$ \\
\hline coordinating energy processes in immune cells during infection & $\begin{array}{l}\text { low level of mitophagy may result in the accumulation of ROS in } \\
\text { the cell and thus carcinogenesis }\end{array}$ \\
\hline mtDNA has antibacterial properties & $\begin{array}{l}\text { mtDNA damage can cause ROS accumulation in the cell and carci- } \\
\text { nogenesis }\end{array}$ \\
\hline $\begin{array}{l}\text { mtDNA can bind to cathelicidins stimulating monocytes and } \\
\text { macrophages toward TNF-a }\end{array}$ & $\begin{array}{l}\text { mtDNA damage in the mitochondrial apoptotic pathway, leading to } \\
\text { increased resistance to anticancer drugs }\end{array}$ \\
\hline $\begin{array}{l}\text { mitochondria activate STING pathway which can lead to apop- } \\
\text { tosis, necroptosis and pyroptosis }\end{array}$ & \\
\hline
\end{tabular}

disease 9 (Cadwell et al., 2008), pancreatic disease related to its endocrine activity, or diseases of the kidneys, lungs and the Paget-Kosi's disease (Orzechowski, 2017). It is assumed that autophagy may be a target of therapy under these conditions, as well as in viral infections and neoplastic processes (Dinkins et al., 2015; NiedźwiedzkaRystwej \& Deptuła, 2009; Ren et al., 2020).

\section{CONCLUSIONS}

Mitochondria, as well as PRR receptors and the autophagy process are important elements for health and disease, including viral infections. Table 2 summarizes the contribution of mitochondria under physiological and pathological states.

It can be concluded that the activity of these elements of the macroorganism affects the processes that determine health. Such a state is constantly evolving over time and most likely arises as a result of adaptation to changing environmental conditions, in which the number of stress factors, including microorganisms, grows and changes, which in the context of the role of the immune system may contribute to the improvement of human and animal health protection.

\section{REFERENCES}

Acuña-Castroviejo D, Rahim I, Acuña-Fernández C, Fernández-Ortiz M, Solera-Marín J, Sayed RKA, Díaz-Casado ME, Rusanova I, López LC, Escames G (2017) Melatonin, clock genes and mitochondria in sepsis. Cell Mol Life Sci 74: 3965-3987. https://doi. org/10.1007/s00018-017-2610-1.

Bandurska K, Król I, Myga-Nowak M (2014) Interferons: between structure and function. Post Hig Med Dosw 68: 428-440 (in Polish)

Bednarczyk M, Krajewska N, Walkiewicz K, Kozieł P, Mazurek U, Muc-Wierzgoń M (2016) PTEN-induced putative kinase 1 (PINK1) in colorectal cancer. Innovations in Polish science: a review of current research topics in the chemical industry. Wydawnictwo Naukowe Sophia 117-126 (in Polish)
Bernardini JP, Lazarou M, Dewson G (2016) Parkin and mitophagy in cancer. Oncogene 36: 1315-1327. https://doi.org/10.1038/ onc. 2016.302

Bernhardt D, Hamann A, Ostewacz HD (2014) The role of mitochondria in fungalaging. Curr Opin Microbiol 22: 1-7. https://doi. org/10.1016/i.mib.2014.09.007

Cadwell K, Liu JY, Brown SL, Miyoshi H, Loh J, Lennerz JK, Kishi C, Kc W, Carrero JA, Hunt S, Stone CD, Brunt EM, Xavier RJ, Sleckman BP, Li E, Mizushima N, Stappenbeck TS, Virgin HW 4th (2008) A key role for autophagy and the autophagy gene Atg1611 inmouse and human intestinal Paneth cells. Nature 456: 259-263. https://doi.org/10.1038/nature0741

Cavallari I, Scattolin G, Silic-Benussi M, Raimondi V, D'Agostino DM, Ciminale V (2018) Mitochondrial proteins coded by human tumor viruses. Front Microbiol 9: 81. https://doi.org/10.3389/ fmicb.2018.00081

Chang HW, Shtessel L, Lee SS (2015) Collaboration between mitochondria and the nucleus is key to long life in Caenorbabditis elegans. Free Radical Biol Med 78: 168-178. https://doi.org/10.1016/j.freeradbiomed.2014.10.576

Chelombitko MA, Chernyak BV, Fedorov AV, Zinovkin RA, Razin E, Paruchuru LB (2020) The role played by mitochondria in FceRI-dependent mast cell activation. Front Immunol 11: 584210. https://doi. org/10.3389/fimmu.2020.584210

Chen IY, Ichinohe T (2015) Response of host inflammasomes to viral infection. Trends Microbiol 23: 55-63. https://doi.org/10.1016/j. tim.2014.09.007

Cherry AD, Piantadosi CA (2015) Regulation of mitochondrial biogenesis and its intersection with inflammatory responses. Antioxid Redox Signal 22: 965-976. https://doi.org/10.1089/ars.2014.6200

Chmielewska M, Skibińska I, Kotwicka M (2017) Mitochondria as target organelles for estrogen action. Post Hig Med Dosw 71: 454-465 (in Polish)

Choi KS (2012) Autophagy and cancer. Exp Mol Med 44: 109-120

Choi YM, Kim H, Lee SA, Lee SY, Kim BJ (2020) A telomerase-derived peptide exerts an anti-hepatitis $\mathrm{B}$ virus effect via mitochondrial DNA stress-dependent type $\mathrm{i}$ interferon production. Front Immunol 11: 652. https://doi.org/10.3389/fimmu.2020.00652

Cloonan SM, Choi AM (2012) Mitochondria: commanders of innate immunity and disease? Curr Opin Immunol 24: 32-40. https://doi. org/10.1016/j.coi.2011.11.001.

Craven L, Alston CL, Taylor RW, Turnbull DM (2017) Recent advances in mitochondrial disease. Annu Rev Genomics Hum Genet 18: 257-275. https://doi.org/10.1146/annurev-genom-091416-035426

Crouse J, Kalinke U, Oxenius A. (2015) Regulation of antiviral T cell responses by type I interferons. Nat Rev Immunol 15: 231-242. https://doi.org/10.1038/nri3806 
Czarnecka AM, Kukwa W, Kwarczyk T, Scińska A, Kukwa A (2011) Mitochondrial dysfunction in tumorigenesis. Post Biol Kom 38: 85110 (in Polish)

de Marcken M, Dhaliwal K, Danielsen AC, Gautron AS, Dominguez-Villar M (2019) TLR7 and TLR8 activate distinct pathways in monocytes during RNA virus infection. Sci Signal 12: eaaw1347. https://doi.org/10.1126/scisignal.aaw1347

Deptuła W, Tokarz-Deptuła B, Niedźwiedzka P (2006) The role and importance of Toll-like receptors. Post Mikrobiol 45: 221-231 (in Polish)

Dinkins C, Pilli M, Kehrl JH (2015) Roles of autophagy in HIV infection. Immunol Cell Biol 93: 11-17. https://doi.org/10.1038/ icb. 2014.88

Durhuus JA, Desler C, Rasmussen LJ (2014) Mitochondria in health and disease - 3rd Annual Conference of Society for Mitochondrial Research and Medicine - 19-20 December 2013, Bengaluru, India. Mitochondrion 20: 7-12. https://doi.org/10.1016/j.mito.2014.10.004.

Fila M, Pawłowska E, Blasiak J (2018) Mitochondria In migrain pathophysiology - does epigenetics play a role? Arch Med Sci 4: 944-954. https://doi.org/10.5114/aoms.2019.86061

Galluzzi L, Brenner C, Morselli E, Touat Z, Kroemer G (2008) Viral control of mitochondrial apoptosis. PLoS Pathog 4: e1000018. https://doi.org/10.1371/journal.ppat.1000018

Gregorczyk KP (2017) Disturbances of mitochondrial dynamics in the course of neurodegenerative, autoimmune and cancer diseases: a review paper. J Health Study Med 4: 57-76 (in Polish)

Grzywa RH (2017) The role of NOD-like receptors (NLRs) in the pathogenesis of metabolic diseases. Post Biochem 63: 205-209 (in Polish)

Halford WP, CD Kemp JA, Isler DJ Davido, PA Schaffer (2001) ICP0, ICP4, or VP16 expressed from adenovirus vectors induces reactivation of latent herpes simplex virus type 1 in primary cultures of latently infected trigeminal ganglion cells. J Virol 75: 6143-6153

Hamacher-Brady A, Brady NR (2015) Mitophagy programs: mechanisms and physiological implications of mitochondrial targeting by autophagy. Cell Mol Life Sci 73: 775-795. https://doi.org/10.1007/ s00018-015-2087-8

Hewson CA, Jardine A, Edwards MR, Laza-Stanca V, Johnston SL (2005) Toll-like receptor 3 is induced by and mediates antiviral activity against rhinovirus infection of human bronchial epithelial cells. J Virol 79: 12273-1229. https://doi.org/10.1128/JVI.79.19.1227312279.2005

Hidvegi T, Ewing M, Hale P, Dippold C, Beckett C, Kemp C, Maurice N, Mukherjee A, Goldbach C, Watkins S, Michalopoulos G, Perlmutter DH (2010) An autophagy-enhancing drug promotes degradation of mutant alpha1-antitrypsin $\mathrm{Z}$ and reduces hepatic fibrosis. Science 329: 229-232. https://doi.org/10.1126/science.1190354

Hou F, Sun L, Zheng H, Skaug B, Jiang QX, Chen ZJ (2011) MAVS forms functional prion-like aggregates to activate and propagate antiviral innate immune response. Cell 146: 448-461. https://doi. org/10.1016/j.cell.2011.06.041

Hu Q, Knight PH, Ren Y, Ren H, Zheng J, Wu X, Ren J, Sawyer RG (2019) The emerging role of stimulator of interferons genes signaling in sepsis: Inflammation, autophagy, and cell death. Acta Physiol (Oxf) 225: e13194. https://doi.org/10.1111/apha.13194

Huang PR, Hung SC, Pao CC, Wang TCV (2015) N-(1-pyrenyl) maleimide induces bak oligomerization and mitochondrial dysfunction in Jurkat cells. BioMed Res Int 2015: e798489. https://doi. org $/ 10.1155 / 2015 / 798489$

Jabłońska A, Paradowska E (2014) The role of RIG-I-like receptors in antiviral responses. Post Hig Med Dosw 68: 541-556 (in Polish)

Jacobs SR, Damania B (2012) NLRs, inflammasomes, and viral infection. I Leukoc Biol 92: 469-477. https://doi.org/10.1189/jlb.0312132

Jiang GM, Tan Y, Wang H, Peng L, Chen HT, Meng XJ, Li LL, Liu Y, Li WF, Shan H (2019) The relationship between autophagy and the immune system and its applications for tumor immunotherapy. Mol Cancer 18: 17. https://doi.org/10.1186/s12943-019-0944-z

Jóźwiak Z, Marczak A (2006) The role of ion channels in apoptosis. Post Bioch 52: 373-382 (in Polish)

Kang D, Kim SH, Hamasaki N (2007) Mitochondrial transcription factor A (TFAM): roles in maintenance of $\mathrm{mtDNA}$ and cellular functions. Mitochondrion 7: 39-44. https://doi.org/10.1016/j. mito. 2006.11.017

Kania E, Pająk B, Orzechowski A (2015) Calcium homeostasis and ER stress in control of autophagy in cancer cells. Biomed Res Int 2015: 352794. https://doi.org/10.1155/2015/352794

Karmakar M, Dubyak GR (2019) Microbes mediate mitochondrial misinformation to misguide neutrophils. J Leukoc Biol 106: 1197-1200. https://doi.org/10.1002/JLB.3CE0819-263

Khan M, Syed GH, Kim SJ, Siddiqui A (2016) Hepatitis B Virus-induced Parkin-dependent recruitment of linear ubiquitin assembly complex (LUBAC) to mitochondria and attenuation of innate immunity. PLoS Pathog 12: e1005693. https://doi.org/10.1371/journal ppat.1005693
Kimura T, Takabatake Y, Takahashi A, Isaka Y (2013) Chloroquine in cancer therapy: a double-edged sword of autophagy. Cancer Res 73: 3-7. https:/ /doi.org/10.1158/0008-5472.CAN-12-2464

Klein $\mathrm{K}$, He K, Younes AI, Barsoumian HB, Chen D, Ozgen T, Mosaffa S, Patel RR, Gu M, Novaes J, Narayanan A, Cortez MA, Welsh JW (2020) Role of mitochondria in cancer immune evasion and potential therapeutic approaches. Front Immunol 11: 573326. https://doi.org/10.3389/fimmu.2020.573326

Labędzka K, Grzanka A, Izdebska M (2006) Mitochondrion and cell death cell. Post Hig Med Dosw (online) 60: 439-446 (in Polish)

Lee HK, Lund JM, Ramanathan B, Mizushima N, Iwasaki A (2007) Autophagy-dependent viral recognition by plasmacytoid dendritic cells. Science 315: 1398-1401. https://doi.org/10.1126/science.1136880.

Lenart J (2017) Mitochondria in cerebral hypoxia. Post Hig Med Dosw (online) 71: 118-128 (in Polish)

Lester SN, Li K (2014) Toll-like receptors in antiviral innate immunity. I Mol Biol 426: 1246-1264. https://doi.org/10.1016/j. jmb.2013.11.024

Liu L, Sakakibara K, Chen Q, Okamoto K (2014) Receptor-mediated mitophagy in yeast and mammalian systems. Cell Res 24: 787-795. https://doi.org/10.1038/cr.2014.75

Liu S, Feng M, Guan W (2016) Mitochondrial DNA sensing by STING signaling participates in inflammation, cancer and beyond. Int I Cancer 139: 736-741. https://doi.org/10.1002/ijc.30074

Luo WW, Li S, Li C, Zheng ZQ, Cao P, Tong Z, Lian H, Wang SY, Shu HB, Wang YY (2017) iRhom2 is essential for innate immunity to RNA virus by antagonizing ER- and mitochondria-associated degradation of VISA. PLoS Pathog 13: e1006693. https://doi. org/10.1371/journal.ppat.1006693

Meyer A, Laverny G, Bernardi L, Charles AL, Alsaleh G, Pottecher J, Sibilla J, Geny B (2018) Mitochondria: an organelle of bacterial origin controlling inflammation. Front. Immunol 9: 536. https://doi. org/10.3389/fimmu.2018.00536

Mills EL, Kelly B, O’Neill LAJ (2017) Mitochondria are the powerhouses of immunity. Nat Immunol 18: 488-498. https://doi. org/10.1038/ni.3704

Mills EL, Kelly B, O’Neill LAJ (2017) Mitochondria are the powerhouses of immunity. Nat Immunol 18: 488-498. https://doi. org/10.1038/ni.3704

Miszczak D, Slonska A (2013) Herpes viruses' survival strategies - latency and apoptosis. Postepy Hig Med Dosw 67: 276-287

Molnar MJ, Kovacs GG (2017) Mitochondrial diseases. Handb Clin Neurol 145: 147-155. https://doi.org/10.1016/B978-0-12-8023952.00010-9

Monlun M, Hyernard C, Blanco P, Lartigue L, Faustin B (2017) Mitochondria as molecular platforms integrating multiple innate immune signalings. J Mol Biol 429: 1-13. https://doi.org/10.1016/j. imb.2016.10.028.

Montgomery MK, Turner N (2015) Mitochondrial dysfunction and insulin resistance: an update. Endoor Connect 4: R1-R15. https://doi. org/10.1530/EC-14-0092

Murphy MP, Hartley RC (2018) Mitochondria as a therapeutic target for common pathologies. Nat Rev Drug Discov 17: 865-886. https:// doi.org/10.1038/nrd.2018.174

Nakahira K, Haspel JA, Rathinam VA, Lee SJ, Dolinay T, Lam HC, Englert JA, Rabinovitch M, Cernadas M, Kim HP, Fitzgerald KA, Ryter SW, Choi AM (2011) Autophagy proteins regulate innate immune responses by inhibiting the release of mitochondrial DNA mediated by the NALP3 inflammasome. Nat Immunol 12: 222-230. https://doi.org/10.1038/ni.1980

Nakai A, Yamaguchi O, Takeda T, Higuchi Y, Hikoso S, Taniike M, Omiya S, Mizote I, Matsumura Y, Asahi M, Nishida K, Hori M, Mizushima N, Otsu K (2007) The role of autophagy in cardiomyocytes in the basal state and in response to hemodynamic stress. Nat Med 13: 619-624. https://doi.org/10.1038/nm1574.

Niedźwiedzka-Rystwej P, Deptuła W (2009) Autophagy - an important immune phenomenon. Postepy Biol Kom 36: 455-446 (in Polish)

Niedźwiedzka-Rystwej P, Ratajczak W, Tokarz-Deptuła B, Deptuła W (2016) Role and characteristics of Inflammasome. Post Biol Kom 43: 250-254

Ohta A, Nishiyama Y (2010) Mitochondria and viruses. Mitochondrion. 11: 1-12. https://doi.org/10.1016/j.mito.2010.08.006.

Orzechowski A (2017) Autophagy, or the big cleanse. Kosmos 66: 153166 (in Polish)

Peixoto PM, Lue JK, Ryu SY, Wroble BN, Sible JC, Kinnally KW (2011) Mitochondrial apoptosis-induced channel (MAC) function triggers a Bax/Bak-dependent bystander effect. Am J Pathol 178: 48-54. https://doi.org/10.1016/j.ajpath.2010.11.014

Pérez-Hernández CA, Kern CC, Butkeviciute E, McCarthy E, Dockrell HM, Moreno-Altamirano MMB, Aguilar-López BA, Bhosale G, Wang H, Gems D, Duchen MR, Smith SG, Sánchez-García FJ (2020) Mitochondrial signature in human monocytes and resistance to infection in $C$. elegans during fumarate-induced innate immune training. Front Immunol 11: 1715. https://doi.org/10.3389/ fimmu.2020.01715 
Pickrell AM, Youle RJ (2015) The roles of PINK1, parkin, and mitochondrial fidelity in Parkinson's disease. Neuron 85: 257-273. https://doi.org/10.1016/j.neuron.2014.12.007.

Piętka G, Kukwa W, Bartnik E, Ścińska A, Czarnecka AM (2008) Mitochondrial DNA mutations in head and neck cancer development. Otolaryngologia Polska 62: 158-164 (in Polish)

Piotrowska A, Bartnik E (2014) The role of reactive oxygen species and mitochondria in aging. Post Bioch 60: 240-247 (in Polish)

Piotrowska A, Jankauskaite E, Bartnik E (2016) Mitochondrial diseases. Postepy Biochem 62: 111-115 (in Polish)

Poniewierska-Baran A, Tokarz-Deptuła B, Deptuła W (2018) Theory threat and danger particles (DAMP). Post Mikrobiol 57: 328-337 (in Polish)

Popkov VA, Zorova LD, Korvigo IO, Silachev DN, Jankauskas SS, Babenko VA, Pevzner IB, Danilina TI, Zorov SD, Plotnikov EY, Zorov DB (2016) Do mitochondria have an immune system? Biochemistry (Mosc) 81: 1229-1236. https://doi.org/10.1134/ S0006297916100217

Poyton RO, Ball KA, Castello PR (2009) Mitochondrial generation of free radicals and hypoxic signaling. Trends Endocrinol Metab 20: $332-$ 340. https://doi.org/10.1016/j.tem.2009.04.001

Pronicka E, Piekutowska-Abramczuk D, Pronicki M (2008) Choroby mitochondrialne u dzieci - podłoże biochemiczne i molekularne, ze szczególnym uwzględnieniem zespołu Leigha. Postepy Biochem 54: 161-168 (in Polish)

Ramos HJ, Gale M Jr. (2011) RIG-I like receptors and their signaling crosstalk in the regulation of antiviral immunity. Curr Opin Virol 1: 167-176. https://doi.org/10.1016/i.coviro.2011.04.004

Reczek CR, Chandel NS (2015) ROS-dependent signal transduction. Curr Opin Cell Biol 33: 8-13. https://doi.org/10.1016/j. ceb.2014.09.010

Ren Z, Zhang X, Ding T, Zhong Z, Hu H, Xu Z, Deng J (2020) Mitochondrial dynamics imbalance: A strategy for promoting viral infection. Front Microbiol 11: 1992. https://doi.org/10.3389/ fmicb.2020.01992

Rivera Vargas T, Benoit-Lizon I, Apetoh L (2017) Rationale for stimulator of interferon genes-targeted cancer immunotherapy. Eur J Cancer 75: 86-97. https://doi.org/10.1016/j.ejca.2016.12.028

Sancho D, Enamorado M, Garaude J (2017) Innate immune function of mitochondrial metabolism. Front Immunol 8: 527. https://doi. org/10.3389/fimmu.2017.00527

Sanz A, Stefanatos RK (2008) The mitochondrial free radical theory of aging: a critical view. Curr Aging Sci 1: 10-21. https://doi. org/10.2174/1874609810801010010

Scott I (2009) Mitochondrial factors in the regulation of innate immunity. Microbes Infect 11: 729-736. https://doi.org/10.1016/j.micinf.2009.04.022.
Shefa U, Jeong NY, Song IO, Chung HJ, Kim D, Jung J, Huh Y(2019) Mitophagy links oxidative stress conditions and neurodegenerative diseases. Neural Regen Res 14: 749-756. https://doi. org/10.4103/1673-5374.249218

Śliwa-Dominiak J, Deptuła W (2011) Review paper RLR receptors - important elements of innate immunity. Cent Eur J Immunol 36: 117-119

Śliwa-Dominiak J, Deptuła W (2011a) The role of TRIM receptors in immunity. Post Biol Kom 38: 549-558 (in Polish)

Śliwa-Dominiak J, Tokarz-Deptuła B, Deptuła W (2014) The role of cells of the immune system and their receptors in viral infections selected data. Post Hig Med Dosw 68: 404-409 (in Polish)

Świderek E, Strządała L (2013) Autophagy and BN1P3 protein in tumorogenesis. Post Hig Med Dośw 67: 363-370 (in Polish)

Tal MC, Iwasaki A (2011) Mitoxosome: a mitochondrial platform for cross-talk between cellular stress and antiviral signaling. Immunol Rev 243: 215-234. https://doi.org/10.1111/j.1600-065X.2011.01038.x

Thompson AJ, Locarnini SA (2007) Toll-like receptors, RIG-I-like RNA helicases and the antiviral innate immune response. Immunol Cell Biol 85: 435-445. https://doi.org/10.1038/sj.icb.7100100

Tokarz P, Blasiak J (2014) Role of mitochondria in carcinogenesis. Acta Biochem Pol 61: 671-678

Tokarz-Deptuła B, Miller T, Deptuła W (2011) Cytokines of the interleukin family 1. Post Mikrobiol 50: 217-221 (in Polish)

Tońska K, Rusecka J, Bartnik E (2018) Mitochondrial diseases, advances in research and treatment. Postepy Biochem 64: 300-303 (in Polish)

Vazquez C, Horner SM (2015) MAVS Coordination of antiviral innate immunity. J Virol 89: 6974-6977. https://doi.org/10.1128/ JVI.01918-14

West AP, Khoury-Hanold W, Staron M, Tal MC, Pineda CM, Lang SM, Bestwick M, Duguay BA, Raimundo N, MacDuff DA, Kaech SM, Smiley JR, Means RE, Iwasaki A, Shadel GS (2015) Mitochondrial DNA stress primes the antiviral innate immune response. $\mathrm{Na}$ ture 520: 553-557. https://doi.org/10.1038/nature14156

West AP, Shadel GS (2017) Mitochondrial DNA in innate immune responses and inflammatory pathology. Nat Rev Immunol 17: 363-375. https://doi.org/10.1038/nri.2017.21

West AP, Shadel GS, Ghosh S (2011) Mitochondria in innate immune responses. Nat Rev Immunol 11: 389-402. https://doi.org/10.1038/ nri 2975

Xagorari A, Chlichlia K (2008) Toll-like receptors and viruses: induction of innate antiviral immune responses. Open Microbiol J 2: 49-59. https://doi.org/10.2174/1874285800802010049

Xu X, Zhang K, Huang Y, Ding L, Chen G, Zhang H, Tong D (2012) Bovine herpes virus type 1 induces apoptosis through Fas-dependent and mitochondriacontrolled manner in Madin-Darby bovine kidney cells. Virol 9: 202. https://doi.org/10.1186/1743-422X-9-202 